\title{
Population ecology of the southern cassowary Casuarius casuarius johnsonii, Mission Beach north Queensland
}

\author{
L. A. Moore
}

Received: 26 July 2006/Revised: 2 November 2006/Accepted: 17 February 2007/Published online: 20 June 2007

(C) Dt. Ornithologen-Gesellschaft e.V. 2007

\begin{abstract}
Little is known of the ecology and population dynamics of the world's largest avian frugivore. This study investigated the population of endangered southern cassowary at Mission Beach, northeast Australia, and examined the problems associated with determining population size and density of this keystone species. Using the results of an intensive field survey aimed at estimating absolute numbers of individual cassowaries, the appropriate sampling methodology for rare and elusive species was explored. Approximately $102 \mathrm{~km}^{2}$ of rainforest was surveyed using $346 \mathrm{~km}$ of search transects. Of a total of 110 cassowaries, there were 49 adults ( 28 male, 19 female, 2 unknown), 28 subadults, 31 chicks, and 2 independent birds of unknown status. This is approximately $35 \%$ of the adult population previously estimated for the Mission Beach area. Overall adult cassowary density was 0.48 adults $/ \mathrm{km}^{2}$; the density of independent birds, i.e. adults and subadults, was $0.78 \mathrm{birds} / \mathrm{km}^{2}$. Mean indicative home range (IHR) for adult females and males was 2.13 and $2.06 \mathrm{~km}^{2}$, respectively. Mean IHR of subadults was smaller at $0.95 \mathrm{~km}^{2}$. It was concluded that the previous practice of surveying small areas at Mission Beach $\left(<4 \mathrm{~km}^{2}\right)$ has led to consistent overestimation of cassowary population density, up to six times its real number. It is shown that a sample plot
\end{abstract}

Communicated by P.H. Becker.

L. A. Moore

School of Tropical Biology, James Cook University,

Townsville 4811, QLD, Australia

L. A. Moore $(\varangle)$

"Cloudhill”, 63 Wooleys Road, Millaa Millaa

4886, QLD, Australia

e-mail: cloudhill@bigpond.com between 5 and $15 \mathrm{~km}^{2}$ is necessary to approximate true cassowary density. These findings have significant application to the conservation of cassowaries in New Guinea and in the Wet Tropics World Heritage Area of Australia.

Keywords Endangered - Keystone - Population size · Density $\cdot$ Home range $\cdot$ Sample area

\section{Introduction}

Cassowaries (genus Casuarius) are large flightless ratites native to the tropical forests of New Guinea and northeast Australia. There are three recognised species: dwarf cassowary Casuarius bennetti, a montane species of New Guinea and New Britain; northern cassowary Casuarius unappendiculatus, endemic to central northern New Guinea; and southern cassowary Casuarius casuarius of Australia and southern New Guinea. Three separate populations of the southern cassowary (Casuarius casuarius johnsonii) exist in Australia (Fig. 1). One is confined to the Wet Tropics region between Paluma Range, just north of Townsville, through to Cooktown; the other two are on Cape York Peninsula, with one in the McIlwraith and Iron Ranges, and the other through the Jardine River catchment area and eastern dunes at the top of the Peninsula. In Australia, the southern cassowary is listed as 'Endangered' under the Environment Protection and Biodiversity Conservation Act 1999. The Nature Conservation Act 1992 (Queensland) classifies the southern (Wet Tropics) population as 'Endangered', while the northern (Cape York) populations are classified as 'Vulnerable'. As with many other rainforest species in the Australian Wet Tropics, its current distribution and abundance are threatened by climate change. 


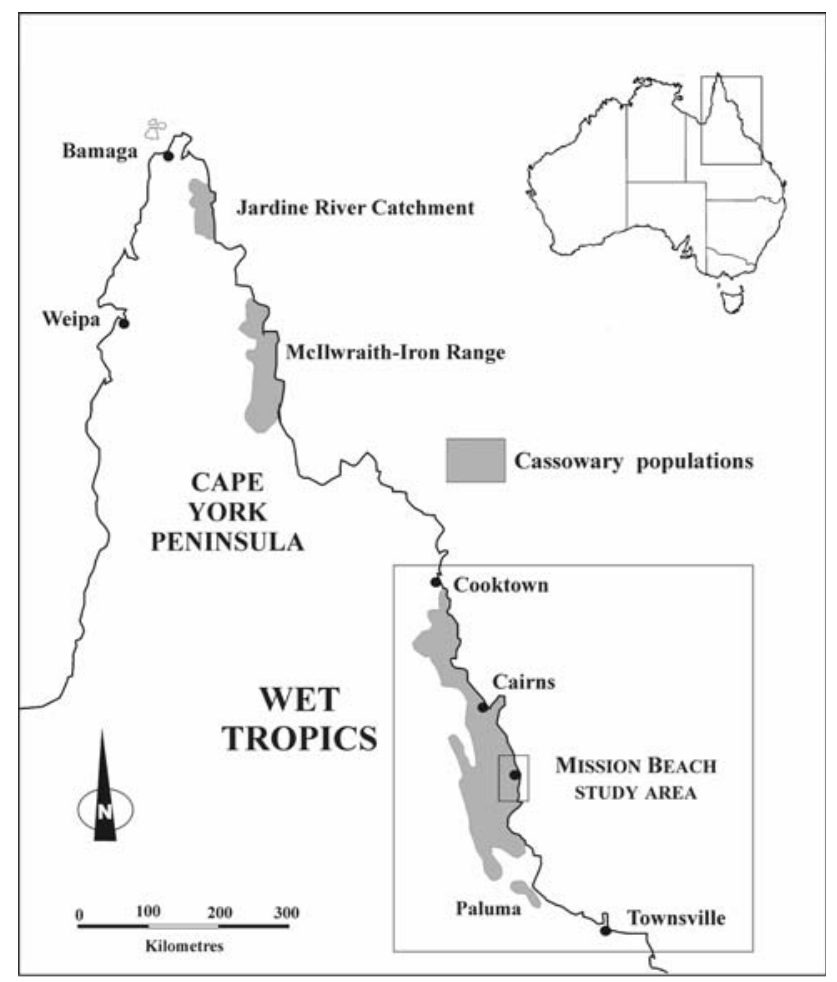

Fig. 1 Distribution of cassowary populations in Australia. Inset shows the location of the Mission Beach study area

General ecology

Australian cassowaries are solitary, highly mobile animals whose preferred habitat is the thick vegetative cover of the rainforest. They are obligate frugivores (Crome 1976; Stocker and Irvine 1983), and adult cassowaries maintain permanent and defended home ranges that vary in size and shape both seasonally and from year to year, depending on environmental conditions and patterns of food abundance (Crome and Moore 1990; Bentrupperbäumer 1998; Moore 2003). Adult plumage is attained at approximately 4 years of age. Although it is not certain that all birds can breed at this age, it is probable that they are capable of breeding successfully within their fifth year. Clutches may vary from two to five eggs. Male cassowaries incubate the eggs for approximately 52 days and care for the young. Studies indicate that approximately $80 \%$ of male cassowaries breed only once every 3 years, with approximately $20 \%$ possibly breeding twice within this period (Bentrupperbäumer 1998; Moore 2003).

Individuals are known to live up to 50 years in captivity and one male cassowary near Cairns was known to breed in the wild over a 25-year period (Moore and Crome 1992). Males bond with two or more females simultaneously during a breeding season (polygyny), while females may breed simultaneously or sequentially with several males (polyandry) (Bentrupperbäumer 1998; Crome and Moore 1990). Although cassowaries may breed at any time of the year when environmental conditions are favourable, the peak breeding season generally extends from June to November.

Foraging is strictly diurnal, the diet predominantly comprising fallen fruits although vertebrate and invertebrate items are eaten (Crome 1976; Stocker and Irvine 1983; Crome and Moore 1990). Cassowaries do not use stones and grit in the gizzard and thus cannot access the nutritious seeds within the fruit (loc cit). They tend, therefore, to feed on fruit with highly nutritious flesh, voiding the seeds completely, often with flesh still adhering (Crome 1976). This gentle treatment makes the bird an efficient disperser of fleshy-fruited seeds and the only major disperser of approximately 100 rainforest plants within the north Queensland forests (Crome and Moore 1990). In tropical forests elsewhere, this role as a major seed dispersal agent is performed by many guilds of birds and mammals, and possibly reptiles. The cassowary, therefore, is considered a "keystone" species, whose loss from the ecosystem may be equivalent to losing several disperser species from other tropical forests (cf. Crome and Moore 1990). This assessment is supported by a study of bird and mammal frugivores in Papua New Guinea (Mack and Wright 2005), which generated an "index of importance" for all 88 frugivorous species using the study area. The study concluded that Casuarius bennetti was a crucial disperser of large-fruited plant species and appeared to be a keystone frugivore for 67 species over $50 \mathrm{~g}$ in weight (loc cit).

Mission Beach cassowary population

Mission Beach, centrally located on the coastline of the Wet Tropics World Heritage Area in northeast Australia (Fig. 1), has been known for many years for its southern cassowary population. Previous studies at Mission Beach have indicated that cassowary numbers are rapidly declining (Crome and Moore 1990; Crome and Bentrupperbäumer 1991; Bentrupperbäumer 1998; Moore 1998, 2003). Factors implicated in this decline include road deaths, dog attacks, disease, increased clearing and development leading to fragmentation and removal of habitat. During the period 1986-2000 (excluding 1989-1990 when no records were kept), 62 cassowary deaths were recorded at Mission Beach, an average death rate of 4-5 birds per year. Of these deaths, one bird was shot; six died from disease (Mycobacterium spp., Aspergillosis spp., Salmonella spp., Pasteurella spp., acute nephritis and severe liver damage); 13 were killed by dogs; and 42 died from collisions with vehicles (Moore 2003). 
The continuing clearing of habitat and known high death rate of cassowaries at Mission Beach emphasises the need for effective conservation strategies to retain a viable population in the area. For this, accurate information regarding the true cassowary population number, their distribution and demography, and an evaluation of the ways in which threatening processes may be interacting to influence extinction probabilities and population persistence are needed (Miller and Lacy 1999). To obtain the ecological and demographic data to drive population viability analysis modelling for the Mission Beach cassowary population, a cassowary field survey of the Mission Beach area was conducted from June to December 2000. The results from this survey are presented here.

\section{Study area}

The study area covers about $130 \mathrm{~km}^{2}$ (Fig. 2) and is centred on Mission Beach, approximately $120 \mathrm{~km}$ south of Cairns. The area surveyed lies across two local government boundaries, those of the Johnstone and Cardwell Shires, and extends from Maria Creek National Park in the north to the mouth of the Hull River in the south. The western arm of the Walter Hill Range delineates the westernmost section of the survey area. The area comprises four main topographic units: lowland plains, coastal ranges, tidal flats and flood plains. The rainforest of the Mission Beach area is separated from the main rainforest block of the Wet Tropics region by extensive agricultural clearing and a major highway, forming a substantial obstacle to east-west cassowary movement. Similar impediments to north-south movement of cassowaries exist at Maria Creek in the north of Mission Beach and at Hull River to the south, although some birds may still swim across. Based on 1992 and 1997 aerial photography, Small (1998) showed that $42 \%$ of critical cassowary habitat (sensu Goosem 1992) on freehold land in the Mission Beach area was cleared in the intervening 6 years. The distributions of cleared land and remaining vegetation at Mission Beach in 1997 are shown on Fig. 2.

\section{Climate}

Mission Beach is located within the wettest region in Australia. The eastern coast between Tully and Babinda has an average annual rainfall in excess of $4,000 \mathrm{~mm}$, with Tully often receiving more than $4,300 \mathrm{~mm}$ per annum. The climate is characterised by very humid to wet summers and relatively mild dry winters. The annual rainfall in the Mission Beach area varies from approximately 2,800 $\mathrm{mm}$ over the coastal lowlands to about 3,200-3,600 mm along the Walter Hill Range, rising to $4,000 \mathrm{~mm}$ a year in the

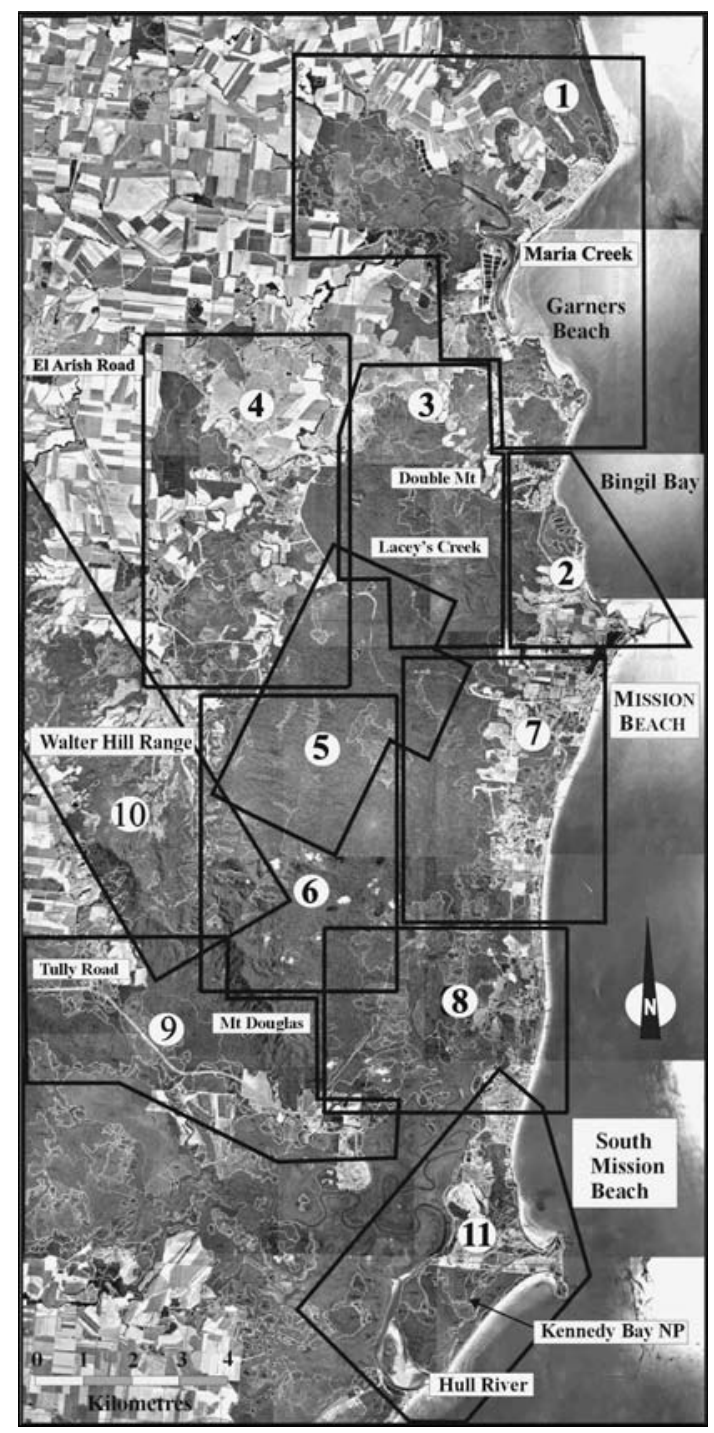

Fig. 2 Land clearing in the Mission Beach study area during September 1997. Place names used in the text are shown along with the locations of search areas $1-11$

area surrounding the coastal peak of Clump Mountain. As there are no long-term rainfall data for the Mission Beach area, the mean monthly and annual rainfall figures for Tully, $20 \mathrm{~km}$ to the west, are presented in Fig. 3.

\section{Vegetation}

The study area comprises a mosaic of vegetation complexes that result from a combination of soil nutrition and soil water levels. Eight major landscape units have been described for the area: rainforests and closed forests; open forests and woodlands; coastal beach ridges and swales; swampy coastal plains; coastal flood plains and piedmont slopes; texture contrast soils with impeded drainage on coastal plains; saline littoral zone; and cleared areas 
Fig. 3 Mean annual rainfall for Tully, north Queensland (34 years of rainfall records)

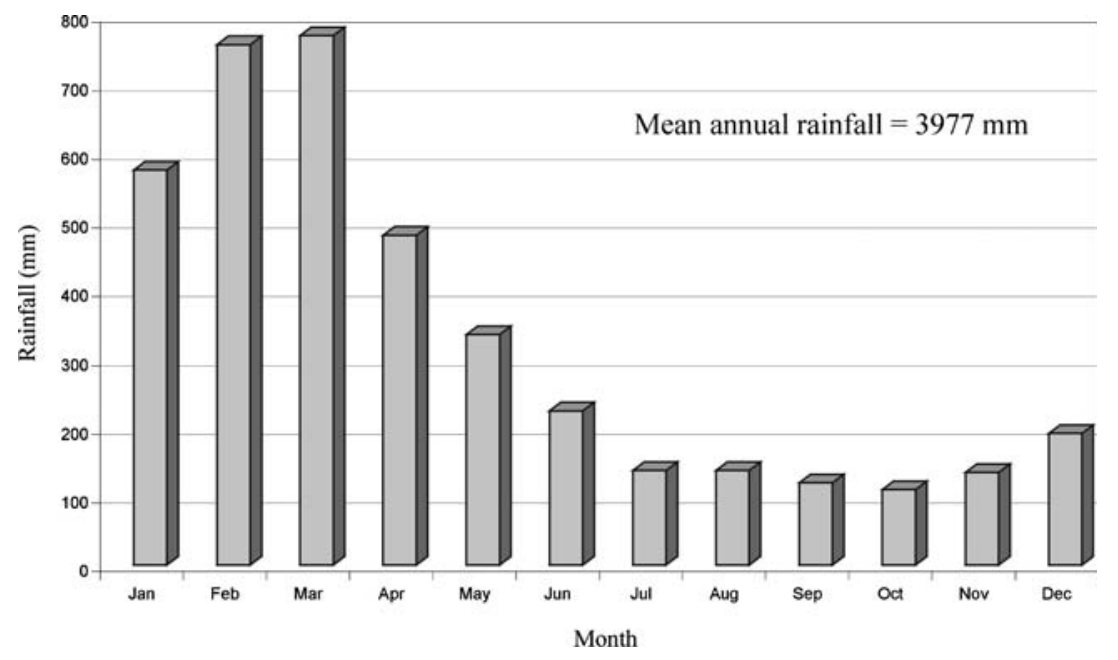

(Goosem 1992). Most of the rainforest is still recovering from past disturbances due to logging and cyclones.

\section{Methods}

Survey methodology

Although research on genetic techniques to identify individual cassowaries from cassowary dung has been underway since 1997, it had not yet been successful at the time of this research and so was not incorporated into the study. The field methodology adopted was to combine detailed mapping of cassowary signs and direct observation of individual cassowaries to determine absolute numbers of individuals. Although sightings of individual birds are the most certain evidence of occurrence, footprints and droppings are the most common signs of a cassowary's presence. The primary field objective, therefore, was to accurately locate, measure and map all cassowary signs, i.e. bird sightings, footprints, droppings and vocalisations. All observations were recorded and plotted onto a field map. As adult and subadult cassowaries weigh $35-80 \mathrm{~kg}$, footprints are regularly left in soft soil along stream banks, megapode scratchings and pig wallows, and often in deep rainforest litter. Although temporary or seasonal food shortage may result in a lack of droppings with which to determine the presence or absence of cassowaries, given suitable weather and soil conditions moving birds will always leave footprints and their presence in an area can be established. Thus, particular effort was made to locate and measure footprints and subsequently locate and identify the birds responsible for making them. Only those footprints that could be accurately measured were used in this study, i.e. footprints affected by mud sag, effects of rain and time, and variance in foot placement were deleted from the analysis. When neighbouring cassowaries had similar footprint measurements or physical characteristics, an immediate search was made to locate and identify the second individual and confirm the existence of two birds.

\section{Mapping}

Using a 1:50,000 topographic map, 11 search areas were defined to provide a complete coverage of the study area (Fig. 2). Search area boundaries were based on clearly recognisable features such as ridge lines, creeks, catchments and roads. A number of search areas were deliberately overlapped to ensure accurate data in what was known to be very difficult terrain, e.g. search areas 5, 6, 8 and 10. Smaller field maps covering $1-2 \mathrm{~km}^{2}$ in area were derived from these search areas for use in the daily field searches. The approximate boundaries of existing vegetation units were marked onto the field maps and survey routes designed. The locations for all data recorded in the field were plotted onto field maps during the field survey and subsequently transferred to a larger base map for interpretation. The vegetation descriptions used in this study area were taken from the 1:100,000 indicative vegetation mapping by Tracey and Webb (1975) and observations made during the field survey.

\section{Ground survey}

Daily field searches were conducted on foot, using transects spaced approximately $100 \mathrm{~m}$ apart. Accessible areas for $50 \mathrm{~m}$ either side of each transect were searched systematically, and all signs of cassowaries were recorded onto field maps. Using compass bearings and landscape features, the survey route was plotted on the field map and a GPS used to establish waypoints whenever possible. On average, an area of approximately $1.5 \mathrm{~km}^{2}$ was searched 
intensively each day. During spring and summer, the light within the forest was sufficient to allow searching from 0800 to 1700 hours $(9 \mathrm{~h})$, and in winter from 0900 to 1530 hours $(6.5 \mathrm{~h})$. The time outside this sampling period was spent re-locating birds from the previous day or walking into or out of search areas.

\section{Field observations}

Procedures for the identification of individual birds followed those for free-living emus Dromaius novaehollandiae by Coddington and Cockburn (1995). In this study, cassowary sightings comprised individual birds or a family group. Adult and subadult cassowaries were individually identifiable based on visible physical characteristics. These features included footprint measurement, size and shape of the casque; presence or absence of markings on exposed surfaces, such as blotches on the casque; visible scars on legs, neck, head, beak; the length and shape of the wattles; the size and sex of the bird; the presence or absence of chicks; and the number and relative ages and size of any chicks accompanying the male parent. Unaccompanied males (no chicks) were identifiable by their relatively small size (in comparison with adult females), and the presence of a distinctive "drooped tail" to their ventral profile. Adult females are clearly larger and present a horizontal line to their ventral profile, lacking the "tail" of the male (Moore 2003). Ages of non-adult birds were determined using observations made in previous studies and by reference to physical descriptions given by Bentrupperbäumer (1998). Subadult cassowaries younger than 9 months of age and no longer dependent on the care of the male parent are termed 'independent' birds in this study.

\section{Survey outcomes}

An area of $101.66 \mathrm{~km}^{2}$ of rainforest, approximately $90 \%$ of the remaining cassowary habitat at Mission Beach, was surveyed on foot over the 6 months of the field survey. The remaining unsurveyed areas comprise regrowth, marginal habitat or freehold land. Search effort used in the analyses amounted to 582.5 field hours, during which $345.8 \mathrm{~km}$ of search transects were walked. A total of 4,729 cassowary signs were recorded, comprising 177 sightings (includes multiple sightings of individuals), 1,198 footprints, 3,347 droppings and 7 vocalisations.

Detailed survey results can be supplied on request to the author.

\section{Calculating cassowary density}

To calculate cassowary density, the Mission Beach search area map was overlaid with a numbered $1 \mathrm{~km}^{2}$ study grid.
Field data from the survey were subsequently mapped onto this grid and all records given an Australian map grid reference (AMG) and study grid location. To avoid inaccuracies associated with small survey area estimates, population densities were obtained by calculating total independent birds (adults and subadults) located over the total area searched, i.e. $101.66 \mathrm{~km}^{2}$. Similar calculations were made to obtain individual adult and subadult densities.

\section{Indicative home ranges}

Home ranges of cassowaries are based on individual sightings and measured footprint locations for each identified bird and were produced by joining the peripheral locations of these observations to each other by connecting the outermost points of the scatter of mapped locations (minimum convex polygon). The area of the resulting polygon was then calculated using a forestry area scale calibrated to the Mission Beach 1:50,000 topographic map. The resultant map of observations represented each bird's home range during the survey period. Home range size estimated in this way is probably an underestimation of the total area used by each bird due to seasonal variation in habitat usage. Therefore, the term Indicative Home Range (IHR) has been used throughout this study.

\section{Results}

\section{Cassowary population size}

A total of 110 cassowaries comprising 49 adults, 28 subadults, 31 chicks and 2 independent birds of unknown status were located during the survey. All but the two unknown cassowaries were sighted and matched to their footprints by measuring prints made while in company of the bird. Of the 49 adults identified, 28 were identified as males, 19 as females and 2 were of undetermined sex. The demographic analyses in this study do not include the two adult birds of unknown sex, and are thus based on 28 known adult males and 19 known adult females. Footprint measurements of located adult and subadult cassowaries have been grouped into size classes and the frequencies of these are shown in Fig. 4. No footprint measurements were taken of chicks still in the company of males.

\section{Cassowary population density}

The population density of adult cassowaries at Mission Beach was 0.48 adults $/ \mathrm{km}^{2}$ (49 adults $/ 101.66 \mathrm{~km}^{2}$ ), i.e. 1 adult per $2.08 \mathrm{~km}^{2}$. This is one-sixth of the density previously estimated for Kennedy Bay National Park and coastal areas of Mission Beach, i.e. 1 adult $/ 0.35 \mathrm{~km}^{2}$ or 


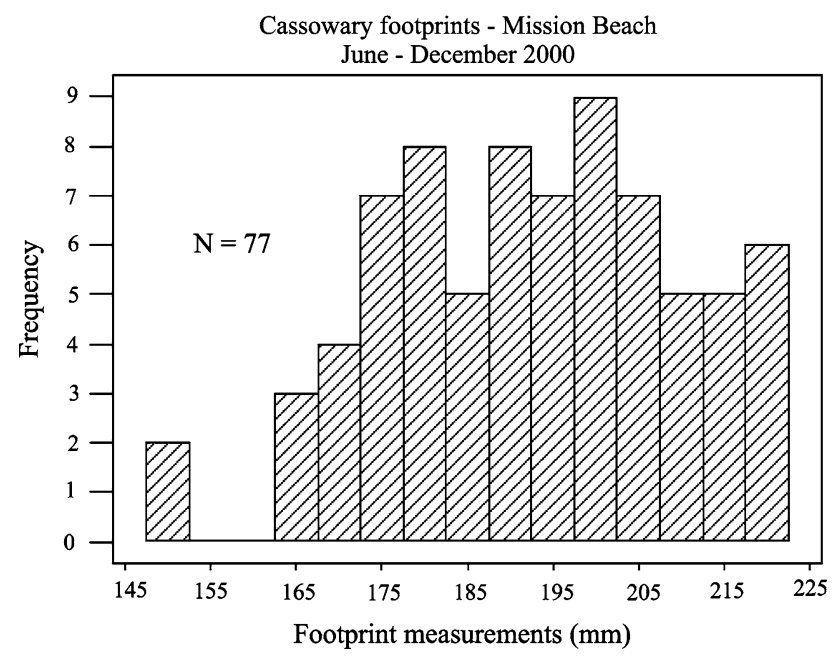

Fig. 4 Footprint measurements of located adult and subadult cassowaries grouped into size classes and the frequencies

3 adults $/ \mathrm{km}^{2}$. A summary of cassowary densities according to age and status is given in Table 1 .

\section{Distribution of cassowaries at Mission Beach}

Cassowary distribution at Mission Beach was tested against a Poisson distribution to determine whether the population was distributed randomly within the rainforest. A frequency table was constructed based on the number of cassowaries occurring within each $1 \mathrm{~km}^{2}$ grid square with the null hypothesis that cassowary occurrence was random throughout the Mission Beach survey area. The resulting Poisson variance: mean ratio was 3.34:2.82 $=1.18$, indicating that the cassowary population was clumped rather than randomly dispersed throughout the study area.

Cassowary sign as an indicator of number of birds

A correlation of the number of cassowaries and all cassowary signs showed there was no relationship between the amount of cassowary signs per $1,000 \mathrm{~m}$ of transect surveyed and the number of birds using an area $\left(R^{2}=0.337\right.$, $P=0.15, n=71)$. This finding confirmed that the number

Table 1 Mission Beach cassowary densities grouped by age and status

\begin{tabular}{lll}
\hline Age and status & $\begin{array}{l}\text { Population densities } \\
\left(\text { bird } / \mathrm{km}^{2}\right)\end{array}$ & $\begin{array}{l}\text { Area densities } \\
\left(\mathrm{km}^{2} / \mathrm{bird}\right)\end{array}$ \\
\hline Adults and subadults & 0.78 & 1.29 \\
Adults & 0.48 & 2.08 \\
Adult males & 0.28 & 3.63 \\
Adult females & 0.19 & 5.35 \\
Subadults & 0.28 & 3.63 \\
\hline
\end{tabular}

of cassowaries in an area cannot be inferred reliably by a simple count of cassowary signs.

Indicative home ranges

A comparison of IHR size for adults and subadults is presented in Fig. 5. Those cassowaries that were recorded only infrequently ( $n=6)$ were excluded from calculations of home range size to avoid biasing the analysis. The IHR for remaining adult cassowaries (males + females $n=43$ ) was $2.09 \mathrm{~km}^{2}(\mathrm{SD}=1.02)$; the mean IHR of adult females ( $n=18)$ was $2.13 \mathrm{~km}^{2}(\mathrm{SD}=0.93)$; and mean IHR of all adult males $(n=25)$ was $2.06 \mathrm{~km}^{2}(\mathrm{SD}=1.10)$. There was no significant difference between combined male home range (non-breeding + breeding) and female home range sizes (two-tailed test: $P=0.82, t=0.23, d f=41$ ), nor between those of breeding males and adult females (twotailed test: $P=0.56, t=0.59, d f=32$ ). Although not quite statistically significant $(P=0.073)$ due to the small sample size, the data suggest an increased area requirement for breeding male cassowaries, i.e. the mean IHR for breeding males $(n=16)$ was $2.35 \mathrm{~km}^{2}(\mathrm{SD}=1.23)$ whereas that for non-breeding males $(n=9)$ was $1.54 \mathrm{~km}^{2}(\mathrm{SD}=0.56)$. If confirmed, this finding has important implications for conservation management in 'at risk' areas. Although subadults ranged over many grid squares, their mean home range $(n=25)$ of $0.95 \mathrm{~km}^{2}(\mathrm{SD}=0.71)$ was significantly smaller than that of combined adult cassowaries $(P=0.0001, t=4.94, d f=66)$.

\section{Breeding observations}

Sixteen males, i.e. $61 \%$ of known males $(n=25)$, were recorded escorting 31 chicks. Chick ages ranged from a few weeks to approximately 9 months old, with the majority of new chicks appearing in September. Although broods of 4-5 chicks have occasionally been sighted at Mission Beach in previous years, all family parties observed in this study contained between one and three chicks, with two chicks being the most common $($ mean $=1.94)$. The mean chick to adult male population ratio was 1.19 chicks per male. Of the 31 chicks observed, $32.3 \%(n=10)$ were brown, i.e. 3-9 months old, and $67.7 \%(n=21)$ striped, i.e. $<3$ months old. While it has been reported that males may sit without eating throughout the incubation period, in this study regular sightings were made of males foraging prior to being seen with newly hatched young.

Subadult population $(<3.5$ years old $)$

Subadults were widely distributed throughout existing adult cassowary home ranges, with 28 individuals located 
Fig. 5 Comparison of indicative home range size for Mission Beach cassowaries. Although there is no significant difference between combined male home range (nonbreeding + breeding) and female home range sizes, the data suggest there may be an increased area requirement for breeding male cassowaries
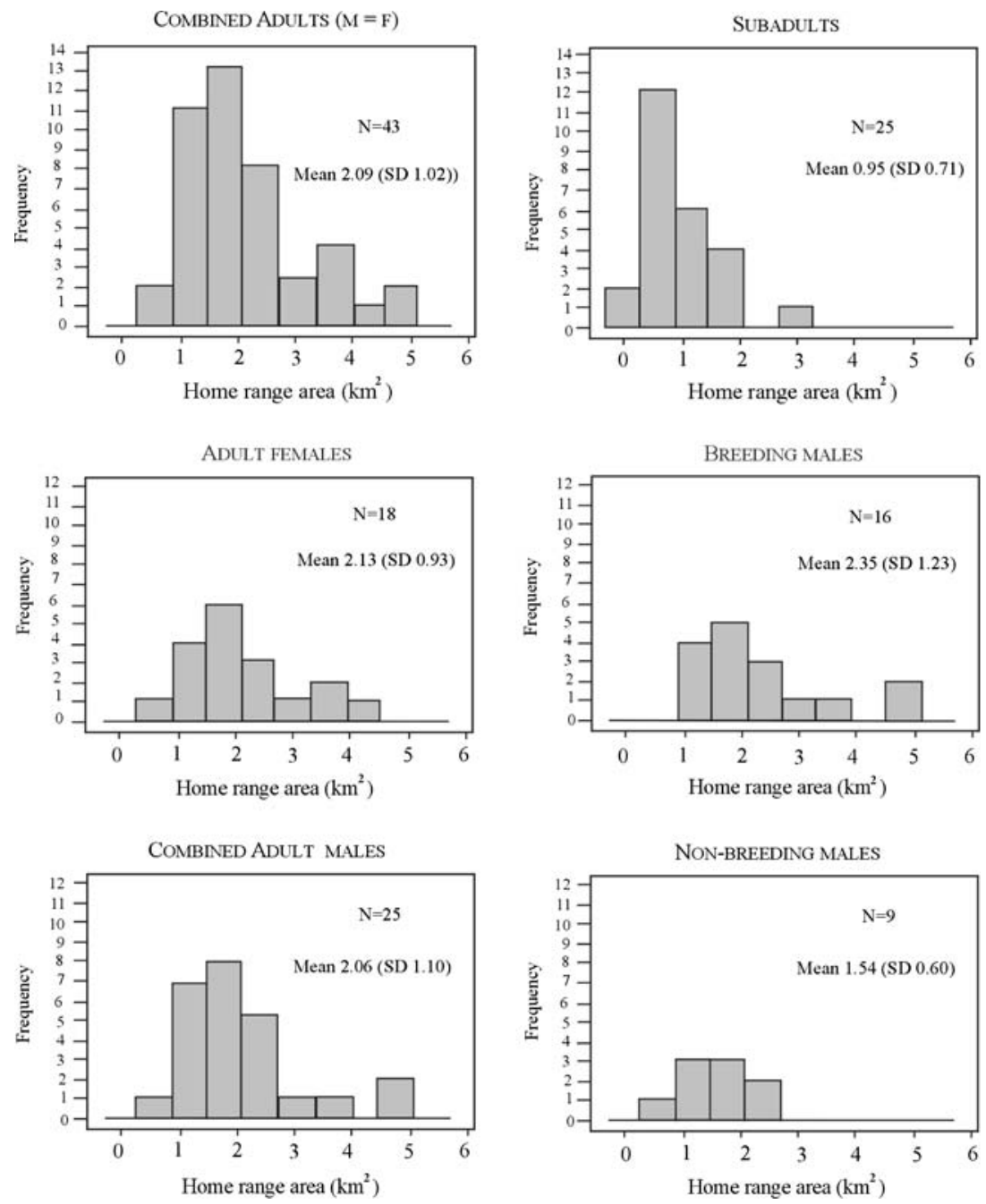

during the survey. Approximately 50\% of these were less than 18 months old, the remainder ranging from 24 to 36 months.

\section{Location of cassowary signs}

Contrary to Westcott (1999), who reported that most cassowary droppings were deposited on tracks, the majority of droppings and footprints were located within the forest. Field observations also showed distinct cassowary usage patterns within the rainforest that expressed a preferential use of existing topographic and landscape features. This preferential usage varied with the shape, width, slope, connectivity, and location of ridges, plateaux, streams and valleys in the overall rainforest landscape. Similar behaviour was also observed in a study on seed dispersal by the dwarf cassowary Casuarius bennetti (Mack 1995).

\section{Discussion}

Adult cassowary population

The field survey located only 49 adult cassowaries, approximately $35 \%$ of the previous estimate of 100-180 adult birds for the area (Crome and Bentrupperbäumer in Goosem 1992). The smaller number is not considered wholly due to bird or habitat loss over the intervening period, but rather an overestimation in previous studies caused by the practice of surveying small areas. The present survey established that apart from 4 adult birds in the Kennedy Bay section of the Hull River National Park, there is no permanent cassowary population on the coast at Mission Beach. Those individuals making occasional or seasonal use of coastal areas had the greater part of their home ranges located further inland. An old nest site located in coastal vegetation at South Mission Beach (Crome and 
Bentrupperbäumer 1991, 1992) nevertheless indicates that cassowaries once bred in this area and on rare occasions may still do so.

\section{Sex ratio}

Bentrupperbäumer (1998) concluded that the sex composition of the Kennedy Bay cassowary population was skewed toward females, i.e. 1 male to 1.25 females. This ratio, however, is likely an artefact created by a relatively small sampling area, i.e. $<400$ hectares. In most polyandrous species, males generally outnumber females (Landsborough-Thompson 1964). This trait is reflected in this study where males outnumbered females, i.e. 28 males to 19 females. The observed sex ratio of 1.47 males to 1 female is greater than that found in the strictly polyandrous emu, i.e. 1.27 males to 1 female (Coddington and Cockburn 1995). Given the small population size, extended juvenile development period, low recruitment rate and high mortality of the Mission Beach cassowaries, bias in the sex ratio raises possible genetic considerations (Moore 2003). Moreover, if the sex ratio is even at birth, the bias could indicate differential mortality by sex.

\section{Indicative home ranges}

Adult male and female home ranges at Mission Beach are of a similar size, and all are considerably larger (mean of combined male and female $=2.08 \mathrm{~km}^{2}$ ) than the $0.7 \mathrm{~km}^{2}$ previously estimated (Crome and Bentrupperbäumer 1991, 1992; Bentrupperbäumer 1998). This study also established that subadults maintained a home range, albeit considerably smaller than that of adults, with most individuals recorded using the same area continually for the entire 6-month field program. These home ranges overlapped those of a number of adults. Maintaining a home range that overlaps multiple adult home ranges has important ecological implications for subadult birds, allowing them to acquire local knowledge of the surrounding habitat and seasonal food resources, and providing increased opportunity for discovering vacant home ranges. Such use of multiple adult home ranges may also assist in reducing agonistic interactions with adults while increasing awareness of the surrounding social system.

\section{Calculating cassowary density at Mission Beach}

Previous cassowary studies at Mission Beach have estimated cassowary density based on the number of independent birds sighted within relatively small search areas, generally $<4 \mathrm{~km}^{2}$. This practice of surveying small areas and extrapolating to larger areas has led to systematic
Table 2 Cassowaries per $1 \mathrm{~km}^{2}$ grid square, illustrating the inaccuracy inherent in using a small survey area for estimating cassowary density. Numbers of individual birds known to occur within each searched grid square were tallied and the birds per grid square tabulated. The results show that there are no grid squares approximating the known cassowary population density of $0.78 \mathrm{birds} / \mathrm{km}^{2}$, i.e. $1 \mathrm{bird} / 1.29 \mathrm{~km}^{2}$

\begin{tabular}{lll}
\hline $\begin{array}{l}\text { No. of birds using } 1 \mathrm{~km}^{2} \\
\text { grid square }\end{array}$ & $\begin{array}{l}\text { Frequencies, i.e. no. of } \\
\text { squares (\% of grid) }\end{array}$ & $\mathrm{km}^{2}$ per bird \\
\hline 1 & $34(26.1)$ & 1 \\
3 & $31(23.8)$ & 0.33 \\
2 & $25(19.2)$ & 0.50 \\
4 & $17(13.2)$ & 0.25 \\
5 & $11(8.5)$ & 0.20 \\
7 & $5(3.8)$ & 0.14 \\
0 & $3(2.3)$ & 0 \\
6 & $2(1.5)$ & 0.17 \\
8 & $1(0.8)$ & 0.13 \\
11 & $1(0.8)$ & 0.09 \\
& $N=130$ & Mean $=0.28$ \\
\hline
\end{tabular}

overestimation of cassowary density. The inaccuracy inherent in using a small survey area for estimating cassowary density is illustrated in Table 2. For this analysis, the Mission Beach search area map (1:50,000) was overlaid with a numbered $1 \mathrm{~km}^{2}$ study grid. Field data from the survey were subsequently mapped and all records given a map reference and study grid location. Totals of individual birds known to occur within each searched grid square were tallied and the birds per grid square tabulated. The results revealed that none of the cassowary totals for any of the 130 grid squares used in this analysis approximated the known cassowary population density of $0.78 \mathrm{birds} / \mathrm{km}^{2}$, i.e. 1 bird/1.29 km $\mathrm{km}^{2}$ (79 independent birds in $101.66 \mathrm{~km}^{2}$ ). Moreover, at a survey scale of $1 \mathrm{~km}^{2}$, there was a 0.74 probability of significantly overestimating the population density. The mean of all $1 \mathrm{~km}^{2}$ grid square totals, i.e. 1 bird per $0.28 \mathrm{~km}^{2}$ (28 hectares), was approximately three times the observed cassowary density (this study) and analogous to previous estimates of adult cassowary density at Kennedy Bay (Crome and Bentrupperbäumer 1991, 1992; Bentrupperbäumer 1998).

These data indicate that sampling in small survey areas of $\pm 1 \mathrm{~km}^{2}$ results in a significant overestimation of cassowary densities and that averaging multiple $1 \mathrm{~km}^{2}$ samples will not correct the sampling error. As cassowaries have home ranges in excess of $2 \mathrm{~km}^{2}$ and a high mobility, survey areas of considerable size are needed to assess their numbers accurately. Depending on the resolution required and the environmental parameters of the target area, it is estimated that a $7-15 \mathrm{~km}^{2}$ sampling plot is required to calculate cassowary density realistically. 
Mission Beach and Daintree cassowary populations

There is considerable similarity between the adult cassowary populations of Mission Beach and the Daintree lowlands, approximately $250 \mathrm{~km}$ to the north (Crome and Moore 1993; Moore 1996a, b, 1999, 2003). Due in part to a smaller study area (Mission Beach $130 \mathrm{~km}^{2} /$ Daintree lowlands $160 \mathrm{~km}^{2}$ ), the adult population size at Mission Beach is slightly less than that found in the Daintree lowlands, i.e. 49 adults (Mission Beach) compared with 54 adults (Daintree). Adult cassowary densities of the two disjunct lowland areas are almost identical, i.e. 0.48 adults/ $\mathrm{km}^{2}$ at Mission Beach compared with 0.45 adults $/ \mathrm{km}^{2}$ in the Daintree lowlands (Moore 2003).

Revised density estimates and cassowary management in Australasia

This study has established that the previous practice of surveying small areas at Mission Beach $\left(<4 \mathrm{~km}^{2}\right)$ has led to overestimation of southern cassowary population density, up to six times its real number (Crome and Bentrupperbäumer 1991, 1992; Bentrupperbäumer 1998). This finding has significant implications for cassowary management strategies in Australia, and also in New Guinea, where cassowaries are traditionally harvested for subsistence and trade. In an evaluation of the sustainability of dwarf cassowary Casuarius bennetti capture and trade in Papua New Guinea (Johnson et al. 2004), the carrying capacity $(K)$ was calculated from studies of dwarf cassowary abundance (Mack 1995; Mack and Wright 1996), and population densities reported for the southern cassowary (Crome and Bentrupperbäumer 1991). The New Guinea study concluded that live offtake rates of $0.06-0.07 / \mathrm{birds}$ $\mathrm{km}^{2}$ were unsustainable or near unsustainable in the management areas studied. As this conclusion was based partly on flawed southern cassowary density estimates, it is probable that maximum sustainable offtake of cassowaries is significantly lower when calculated using the revised densities reported in this study. This outcome would result in a concomitant reduction in the annual sustainable level of live offtake.

\section{Conclusion}

This study showed that there is no possibility of determining true cassowary densities at a survey scale of $1 \mathrm{~km}^{2}$ or less and, as such, previous field studies using small-area surveys have considerably overestimated cassowary densities. There is a need, therefore, to re-examine cassowary management strategies in Australia and New
Guinea that may be predicated on these flawed population estimates. It is suggested that the field methodology used in this study may be appropriate for a similar communitybased assessment of cassowary harvesting in Papua New Guinea.

\section{Zusammenfassung}

Populationsökologie des Helmkasuars Casuarius casuarius johnsonii, Mission Beach, North Queensland

Die Kenntnisse zur Ökologie und Populationsdynamik der größten frugivoren Vogelart sind dürftig. Die Arbeit untersucht die gefährdete Population des Helmkasuars in Mission Beach im nordöstlichen Australien und widmet sich den Problemen der Ermittlung von Populationsgröße und -dichte dieser Vogelart. $102 \mathrm{~km}^{2}$ Regenwald wurden von $346 \mathrm{~km}$ Transekten aus inspiziert, um absolute Individuenzahlen $\mathrm{zu}$ ermitteln und die angemessene Erfassungsmethode für seltene und heimliche Arten $\mathrm{zu}$ erarbeiten. Insgesamt wurden 110 Helmkasuare ausgemacht (49 Altvögel, davon 28 Männchen, 12 Weibchen, 2 unbestimmt - 28 Subadulte, 31 Küken und 2 Tiere mit unbekanntem Status). Damit ergaben sich ungefähr 35\% der Altvogelpopulationsgröße, die vormals für diese Region geschätzt wurde. Die Populationsdichte adulter Helmkasuare betrug 0,48, einschließlich der Subadulten 0,78 Individuen $/ \mathrm{km}^{2}$. Im Mittel hatten adulte Weibchen einen Home Range von $2,13 \mathrm{~km}^{2}$ und Männchen von $2,06 \mathrm{~km}^{2}$. Dagegen war der Home Range der Subadulten mit $0,95 \mathrm{~km}^{2}$ kleiner. Die Ergebnisse legen den Schluss nahe, dass frühere Erhebungen auf der Basis kleiner Probeflächen (weniger als $4 \mathrm{~km}^{2}$ ) $\mathrm{zu}$ regelmäßigen Überschätzungen der Populationsdichte des Helmkasuars bei Mission Beach führten, und zwar bis zum sechsfachen der realen Größe. Probeflächen zwischen $5-15 \mathrm{~km}^{2}$ sind erforderlich, um die Helmkasuar-Dichte verlässlich $\mathrm{zu}$ schätzen. Die Befunde sind bedeutsam für den Schutz der Kasuare in Neuguinea und in den feuchten Tropen Australiens.

Acknowledgments I am grateful to Professor Chris Johnson for supervising the original M.Sc. project and providing constructive comments on this manuscript. My wife Dr. Nicole Moore also contributed significantly, both with her editing and insightful observations. I would also thank Dr. Andrew Mack, Prof. Dr. Peter H. Becker, and an anonymous reviewer for helpful and constructive comments. My greatest thanks, however, go to the people of Mission Beach and in particular those individuals who make up the Community for Coastal and Cassowary Conservation (C4). Their knowledge of the local cassowary population and their untiring efforts to conserve the species at Mission Beach are legendary. This study was conducted within the guidelines imposed by an Ethics Approval granted by James Cook University, Townsville, Australia. 


\section{References}

Bentrupperbäumer J (1998) Reciprocal ecosystem impact and behavioural interactions between cassowaries, Casuarius casuarius and humans, Homo sapiens. Ph.D. Thesis, James Cook University, Townsville

Coddington C, Cockburn A (1995) The mating system of free-living emus. Aust J Zool 43:365-372

Crome F (1976) Some observations on the biology of the cassowary in northern Queensland. Emu 76:8-14

Crome F, Bentrupperbäumer J (1991) Management of cassowaries in the fragmented rainforests of north Queensland (Phase 1). A consultancy report to The Endangered Species Program of the Australian National Parks and Wildlife Service

Crome F, Bentrupperbaumer J (1992) Cassowaries in north Queensland II: Fieldwork in 1992. A consultancy report to The Endangered Species Program of the Australian National Parks and Wildlife Service

Crome F, Moore L (1990) Cassowaries in northeast Queensland: a report of a survey and a review and assessment of their status and conservation and management needs. Aust Wildl Res 17:369385

Crome F, Moore L (1993) Cassowary populations and their conservation between the Daintree River and Cape Tribulation. Vol. 2 Background, survey results and analysis. A CSIRO report to the Douglas Shire Council

Environment Protection and Biodiversity Conservation Act 1999. Commonwealth Government Printer, Australia

Goosem S (1992) Draft Management Plan Mission Beach Area, North Queensland. Queensland Department of Environment and Heritage Report, Far Northern Region, Cairns

Goosem S (2000) Renomination of the cassowary on the Commonwealth Endangered Species Schedule. Queensland Government Printer, Brisbane

Johnson A, Bino R, Igag P (2004) A preliminary evaluation of the sustainability of cassowary (Aves: Casuariidae) capture and trade in Papua New Guinea. Anim Cons 7:129-137

Landsborough-Thompson A (1964) A new dictionary of birds. Thomas Nelson and Sons Ltd., London and Edinburgh

Mack A (1995) Distance and non-randomness of seed dispersal by the dwarf cassowary Casuarius bennetti. Ecography 18(3):286-295
Mack A, Wright D (2005) The frugivore community and the fruiting plant flora in a New Guinea rainforest: identifying keystone frugivores. In: Lawrence Dew J, Jean Philippe Boubli (eds) Tropical fruits and frugivores: the search for strong interactors. Springer, The Netherlands, pp 184-203

Mack A, Wright D (1996) Notes on occurrence and feeding of birds at the Crater Mountain Biological Research Station, Papua New Guinea. Emu 96:89-101

Miller P, Lacy R (1999) VORTEX: A stochastic simulation of the extinction process. Version 8 users manual. Conservation Breeding Specialist Group

Moore L, Crome F (1992) Report on a survey of cassowary populations in the Whitfield Range, north Queensland. Internal Research Report, CSIRO

Moore L (1996a) Part 1: cassowary monitoring program, Daintree lowlands: report for the Wet Tropics Management Authority

Moore L (1996b) Part 2: cassowary monitoring program, Daintree lowlands: report for Wet Tropics Management Authority

Moore L (1998) Cassowary conservation roads: a management strategy and road upgrade assessment for El Arish and TullyMission Beach roads, Mission Beach. Report for Queensland Department of Main Roads

Moore L (1999) Cassowary management plan I. Daintree. Report for the Wet Tropics Management Authority, Cairns, Queensland

Moore L (2003) Ecology and population viability analysis of the southern cassowary (Casuarius casuarius johnsonii): Mission Beach, North Queensland. MSc thesis, James Cook University, Queensland

Nature Conservation Act 1992. Queensland Department of Environment and Heritage. Brisbane, Australia

Small A (1998) Vegetation of the Maria Creek to Hull River Coastal Area. In: Far North Queensland 2010 Regional Environment Strategy. Queensland Government Printer

Stocker G, Irvine A (1983) Seed dispersal by cassowaries (Casuarius casuarius) in north Queensland's rainforest. Biotropica 15:170 176

Tracey J, Webb L (1975) Vegetation of the humid tropical region of North Queensland. CSIRO Division of Plant Industry, Indooroopilly

Westcott D (1999) Counting cassowaries: what does cassowary sign reveal about their abundance? Aust Wildl Res 26:61-67 